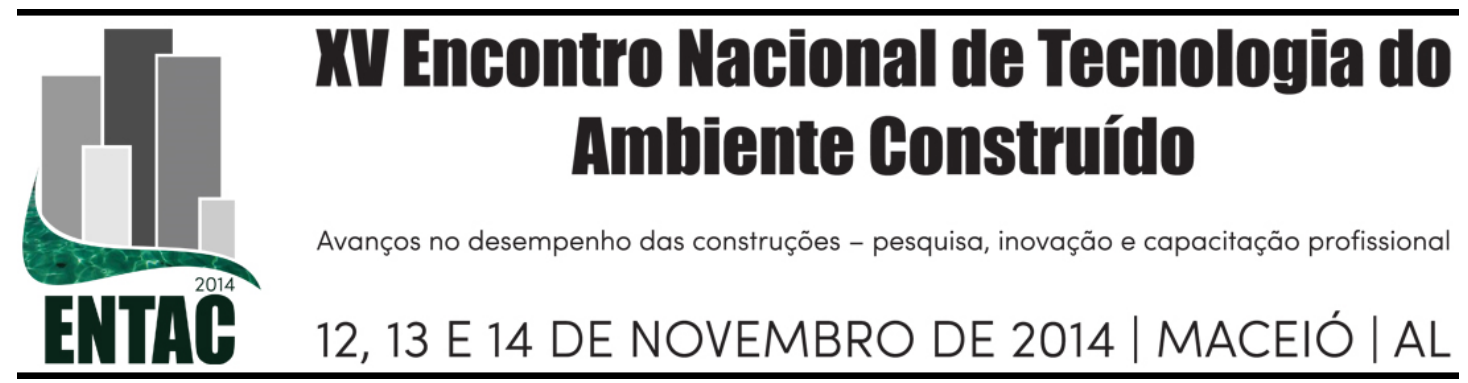

\title{
AVALIAÇÃO DO MUSEU DA IMAGEM E DO SOM NA CIDADE DO RIO DE JANEIRO PELOS REQUISITOS DO QUALIVERDE
}

PAMPURI, Maria F. (1); SALGADO, Monica S. (2)

(1) PROARQ/FAU - Universidade Federal do Rio de Janeiro, pampurimariaflor@gmail.com (2) PROARQ/FAU - Universidade Federal do Rio de Janeiro, monicassalgado@ ufrj.br

\begin{abstract}
RESUMO
Recentemente a Prefeitura da Cidade do Rio de Janeiro apresentou uma proposta para avaliação dos requisitos ambientais em projetos. Elaborado por técnicos das secretarias municipais de Meio Ambiente e Urbanismo, o QUALIVERDE lista medidas voltadas para a sustentabilidade ambiental, diretrizes e estratégias que podem ser adotadas durante o desenvolvimento do projeto. A diferença entre esta proposta e outras iniciativas para produção de edificações sustentáveis reside nos benefícios fiscais oferecidos, que impactam os custos do IPTU (Imposto Predial e Territorial e Urbano), ITBI (Imposto de Transmissão de Bens Imóveis), entre outros. Considerando-se que os eventos esportivos que serão realizados na cidade provocaram uma explosão de novas construções, entende-se que a adoção de qualquer estratégia ambiental será crucial para o adequado desempenho ambiental das novas edificações. No entanto, apesar da existência de certificação promovida pela Prefeitura, observa-se que os novos projetos têm dado preferência a outras certificações - em particular a certificação norte-americano LEED. Assim, este trabalho apresenta os resultados da pesquisa sobre o novo Museu da Imagem e do Som, que está sendo construído na praia de Copacabana. Este projeto está sendo desenvolvido considerando as exigências da certificação LEED NC (novas construções), e a pesquisa busca confrontar as características do projeto estabelecidas para este edifício com os requisitos ambientais estabelecidos pelo QUALIVERDE. Os resultados indicam que nem sempre as diretrizes para avaliação de projetos propostas pelas certificações são equivalentes, ocorrendo, em muitas ocasiões, pontuações muito discrepantes para uma mesma característica de projeto. Ou seja, o fato de uma edificação atender satisfatoriamente aos requisitos ambientais de determinada certificação não necessariamente significa que será capaz de cumprir satisfatoriamente com os requisitos de outro sistema de avaliação ambiental.
\end{abstract}

Palavras-chave: construções sustentáveis, qualidade ambiental, certificações ambientais

\begin{abstract}
The Municipality of Rio de Janeiro City has recently presented a proposal for a new environmental rating system for buildings. QUALIVERDE certification indicates design guidelines and strategies that can be adopted during the design process in order to guarantee high quality environmental performance in buildings. The differential of this proposal lies in the tax benefits offered, which impacts the cost of property tax (Territorial and Urban Property Tax - IPTU ), ITBI Tax ( Transfer of Real Property), among others. Considering that the sports events that are going to be held in the city have provoked an explosion of new construction, it is understood that the adoption of any environmental strategy is crucial for the adequate performance of new buildings. However, despite the existence of Rio's environmental certification, one observes that the new projects have given preference to other certifications particularly the north American LEED certification. Thus, this paper presents results of the research about the new Museum of Image and Sound, on Copacabana beach. This project is being developed considering the requirements of LEED certification, and the research seeks to confront the design features set for this building with the environmental requirements set by QUALIVERDE. The results indicate that guidelines for environmental rating systems are not necessarily equivalent, occurring on many occasions, very discrepant scores for the same design feature. Ie, the fact that a building
\end{abstract}


satisfactorily meets the environmental requirements of a certification does not necessarily mean it will be able to fulfill satisfactorily the requirements of another system.

Keywords: sustainable construction, environmental quality, environmental certifications

\section{INTRODUÇÃO}

A cidade do Rio de Janeiro tem assistido ao crescimento da indústria da construção civil, impulsionado particularmente pelos jogos da Copa do Mundo (2014) e as Olimpíadas de 2016. Esses dois grandes eventos esportivos detonaram um processo de remodelação urbana e produção de edificações que, em última instância, deixarão um legado aos cidadãos cariocas.

Uma das questões a serem consideradas pelos novos projetos é quanto à sustentabilidade ambiental, tendo em vista que a indústria da construção civil é um dos setores que causa maior impacto ao meio ambiente devido à utilização dos recursos naturais em grande escala.

Diante desse quadro, entende-se a necessidade de avaliar se de fato as novas edificações estão sendo produzidas considerando os aspectos relacionados com a sustentabilidade ambiental. Nesse sentido, tem destaque a iniciativa da Prefeitura da Cidade do Rio de Janeiro, que elaborou uma certificação própria: o QUALIVERDE. Essa certificação consiste num método capaz de avaliar o desempenho ambiental das edificações atribuindo uma pontuação para cada medida economizadora adotada.

Entretanto, como essa certificação é local (ou seja, exclusiva para a cidade do Rio de Janeiro), os profissionais preferem optar por certificações reconhecidas internacionalmente. Foi o que ocorreu na produção do novo Museu da Imagem e do Som, que está sendo construído na Praia de Copacabana. Este projeto considera os requisitos da certificação ambiental LEED para Novas Construções (LEED NC).

Dessa forma, este artigo apresenta os resultados da pesquisa de iniciação científica que analisou o projeto do Museu da Imagem e do Som para verificar se existe aderência entre os requisitos da certificação LEED NC e o certificado QUALIVERDE. O objetivo foi avaliar se a metodologia proposta pela Prefeitura do Rio de Janeiro estaria alinhada em termos de exigências ambientais ao método norte-americano a partir da análise das características ambientais incorporadas àquele projeto.

\section{SUSTENTABILIDADE AMBIENTAL E SISTEMAS DE CERTIFICAÇÃO}

As discussões em torno das metas para a construção sustentável se intensificaram a partir da publicação, em 2002, da Agenda 21 para a construção sustentável nas Nações em Desenvolvimento. De acordo com aquele documento, estão entre os principais aspectos a serem considerados no atendimento aos objetivos ambientais: 0 estabelecimento de metas para o desempenho ambiental das edificações, as mudanças nas práticas de gestão do processo de projeto e construção, e a implantação de uma nova cultura dentro do setor da construção civil, onde todos passariam a valorizar os recursos naturais (água, ar, terra) e as possibilidades de reciclagem e reuso dos materiais. (CIB, 2002)

A partir da publicação daquele documento, intensificaram-se as iniciativas em torno da produção de edificações sustentáveis, com a disseminação de diferentes métodos de auxílio ao projeto com qualidade ambiental. 
Apesar da grande quantidade de certificações ambientais desenvolvidas internacionalmente, com destaque para o método inglês BREEAM (Building Research Establishment Environmental Assessment Methodology) e o método SBTool (Sustainable Building Tool) desenvolvido pelo iiSBE (International Initiative for a Sustainable Built Environment), duas se destacaram na realidade brasileira, e vem sendo adotadas por alguns empreendedores e construtores:

- a metodologia $L E E D^{\mathrm{TM}}$ para avaliação do desempenho ambiental de edificações (The Leadership in Energy and Environmental Design Green Building RatingSystem) desenvolvida pelos norte-americanos;

- o método HQE® (Haute Qualité Environmentale) - desenvolvido pelo governo francês, que especifica metas ambientais a serem perseguidas no desenvolvimento do projeto da edificação. No Brasil esse método deu origem à certificação AQUA.

A busca pela validação da qualidade ambiental das construções tem levado ao interesse nos métodos que efetivamente facilitem a produção de edificações sustentáveis. No âmbito dessa discussão, os técnicos da Prefeitura do Rio de Janeiro desenvolveram o QUALIVERDE. Instituído pelo Decreto ${ }^{\circ}$ 35745, de 06 de junho de 2012, trata-se de um processo opcional e aplicável aos projetos de edificações novas ou existentes, de uso residencial, comercial, misto ou institucional. Com o objetivo de discutir e comparar esses métodos, serão apresentadas resumidamente as principais características das certificações LEED e QUALIVERDE.

\subsection{0 método LEED}

O método Norte-Americano LEED - Leadership in Energy and Environmental Design (Liderança em Energia e Design Ambiental) consiste em um sistema internacional de certificação e orientação ambiental para edificações, utilizado em 143 países, que tem o intuito de incentivar a transformação do projeto, obra e operação das edificações, sempre com foco na sustentabilidade. Entre as dimensões de sustentabilidade consideradas pela certificação LEED tem-se (UGBC,2014):

- Espaço sustentável (referentes à escolha do terreno e aspectos locacionais);

- Eficiência no uso da água - valorização das inovações para uso racional da água, visando a reduzir o consumo de água potável e reuso dos recursos;

- Energia e atmosfera - promoção da eficiência energética da edificação por meio de estratégias de medição e comissionamento de sistemas;

- Materiais e recursos - uso de materiais com baixo impacto ambiental, de forma a reduzir a geração de resíduos;

- Qualidade ambiental interna - escolha de materiais com baixa emissão de compostos orgânicos voláteis, controle de sistemas, conforto térmico e priorização de espaços com vistas externas e luz natural.

- Inovação e processos - incentivo à adoção de medidas projetuais não contempladas pela certificação;

- Créditos de prioridade regional - priorização, considerando as diferenças ambientais, sociais e econômicas da região.

O sistema de avaliação é baseado em créditos que são ponderados para gerar a classificação de desempenho ambiental do empreendimento. $\mathrm{O}$ método estabelece 
sistemas de certificação conforme o escopo pretendido, sendo possível escolher desde o método mais abrangente, como o LEED-NC (certificado para novas construções e ou grandes reformas) até o mais específico, como o LEED-CI (para interiores de edificações comerciais), entre outros.

Pesquisa realizada por Pereira et al (2013) indicou que no mercado imobiliário, as edificações comerciais tem dado preferência à certificação LEED CS (Core \&Shell), enquanto na produção de edificações residenciais multifamiliares os empreendedores tem preferido o processo AQUA. As autoras acrescentam que a procura pelo LEED CS vem ao encontro à demanda atual do mercado pelos edifícios comerciais, com certificação da envoltória, suas áreas comuns e os sistemas da edificação. Incorporadores procuram essa certificação na busca de valor agregado ao preço de comercialização das salas comerciais ou no seu valor de locação.

\subsection{A proposta do QUALIVERDE}

A certificação proposta pela Prefeitura do Rio de Janeiro visa à estimular a adoção de normas e medidas sustentáveis e incentivar a adoção de soluções visando à redução da emissão de gases do efeito estufa. O método pode ser aplicado em antigas ou novas construções, de uso residencial, comercial, misto ou institucional. (COMPUR, 2014)

A qualificação QUALIVERDE será obtida pelo empreendimento que adotar ações e práticas de sustentabilidade, correspondendo cada ação a uma pontuação determinada, existindo dois níveis de qualificação:

- QUALIVERDE - para o empreendimento que atingir, no mínimo, 70 pontos;

- QUALIVERDE TOTAL - para o empreendimento que atingir, no mínimo, 100 pontos.

O QUALIVERDE lista 38 medidas relativas à gestão da água, eficiência energética e projeto. Aos pontos obtidos nas categorias definidas, somam-se, ainda, pontuações específicas, que visam a incentivar práticas sustentáveis, tais como: realização de retrofit em edificação existente; medição individualizada da água potável nas edificações existentes (para as edificações novas já é uma exigência); construção de reservatórios de retardo; certificação ambiental obtida em outro programa (AQUA, LEED, outros); tecnologias inovadoras.

Uma das características do QUALIVERDE que o diferencia das demais propostas são os benefícios fiscais aos empreendimentos que conquistarem essa certificação. (Projeto de Lei $\mathrm{n}^{\circ}$ 1415/2012).

O fato do QUALIVERDE considerar positiva e pontuar a obtenção de outra certificação ambiental levou ao interesse na comparação entre os métodos, de forma, inclusive, a identificar se as proposições estariam alinhadas entre si.

\section{ESTUDO DE CASO: O MUSEU DA IMAGEM E DO SOM (MIS), COPACABANA - RIO DE JANEIRO}

O projeto do museu foi realizado pelo escritório americano Diller Scofidio + Renfro, Arquitetos Elizabeth Diller e Ricardo Scofidio e Daniela Thomas e Felipe Tassara na museografia, tendo como precursor da nacionalização do projeto o escritório Índio da Costa AUDT.

O edifício divide-se em setores definidos da seguinte forma: "Baixo Atlântica" - referese ao lobby, principal ponto de encontro; "Espírito Carioca"- relacionado ao espaço que contará com três salas dedicadas ao humor, rebeldia e à festa; "Música" - neste 
pavimento serão apresentadas as grandes produções musicais da zona norte e sul carioca; "Alegres Trópicos" - de acordo com o projeto neste pavimento estará em exposição o acervo dedicado à Carmem Miranda, personagem síntese do Museu da Imagem e do Som; "É sol, é sal é sul" - localizando no andar superior, permitirá a visualização da história da cidade (evolução urbana do Rio de Janeiro). Além desses pavimentos, o projeto conta com um espaço de lazer no subsolo, além de um cineauditório com capacidade para 280 pessoas. O terraço funcionará como um mirante, democratizando a vista da praia de Copacabana. (FUNDAÇÃO ROBERTO MARINHO, 2014)

Desde o lançamento do concurso decidiu-se pelo atendimento dos requisitos de sustentabilidade e o escritório responsável pelo projeto contatou a empresa Casa do Futuro no Rio de Janeiro para buscar atender às metas da certificação LEED Novas Construções. (MIS, 2014) As figuras 1, 2 e 3 ilustram o andamento das obras, com significativo avanço a partir de maio de 2014.
Figura 1 - Nov./2013
Figura 2 -Maio/2014
Figura 3 - Julho/2014

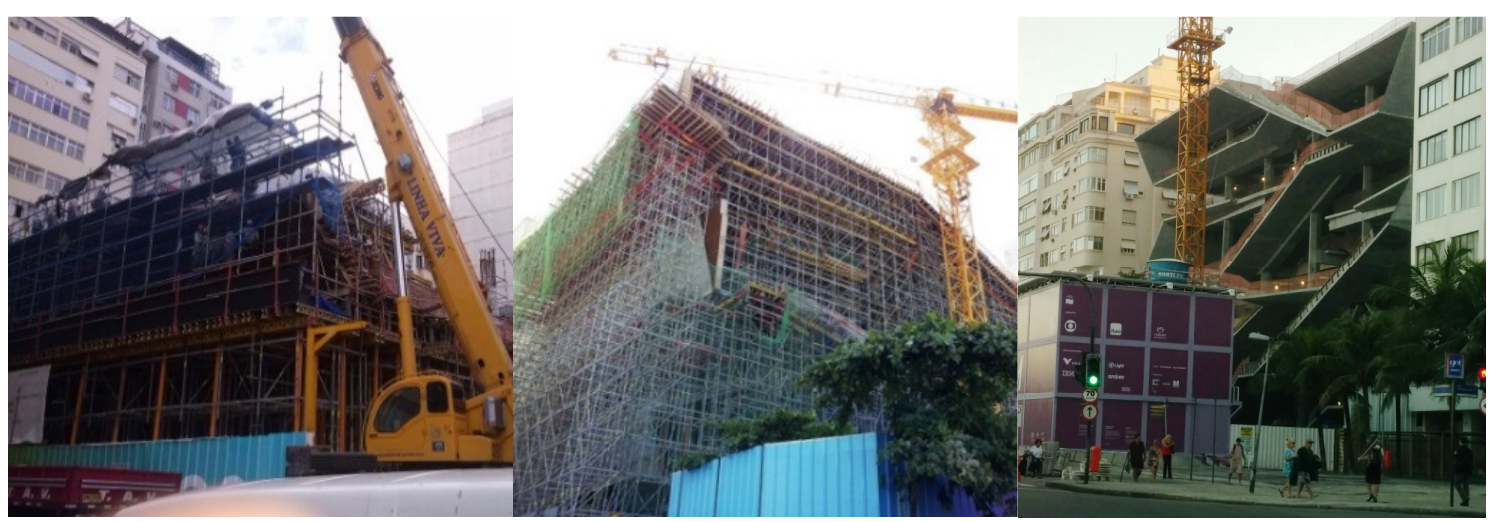

Fonte: as autoras

Fonte: as autoras

Fonte: as autoras

\section{REQUISITOS DO LEED-NC E DO QUALIVERDE: ANÁLISE COMPARATIVA}

Para subsidiar a análise proposta nessa pesquisa, realizou-se contato as instituições envolvidas de forma a ter acesso aos dados de projeto e identificar os requisitos da certificação LEED NC que estariam sendo contemplados pelo projeto do MIS. O Quadro 1 apresenta os dados do projeto com a provável pontuação obtida, e estabelece a correlação entre os requisitos da certificação LEED Novas Construções e os requisitos da certificação QUALIVERDE.

A certificação LEED é concedida no nível "certificado", quando a pontuação obtida pelo projeto atinge entre 40 a 49 pontos. O nível LEED Prata é concedido quando a pontuação varia entre 50-59. Para obter a classificação LEED Ouro, o projeto deve atingir de 60 - 79 pontos e o nível mais alto da certificação, LEED Platina, é concedido às edificações que obtiverem pontuação acima de 80 pontos. 
Quadro 1: Museu da Imagem e do Som a partir dos requisitos do QUALIVERDE e LEED NOVAS CONSTRUÇÕES

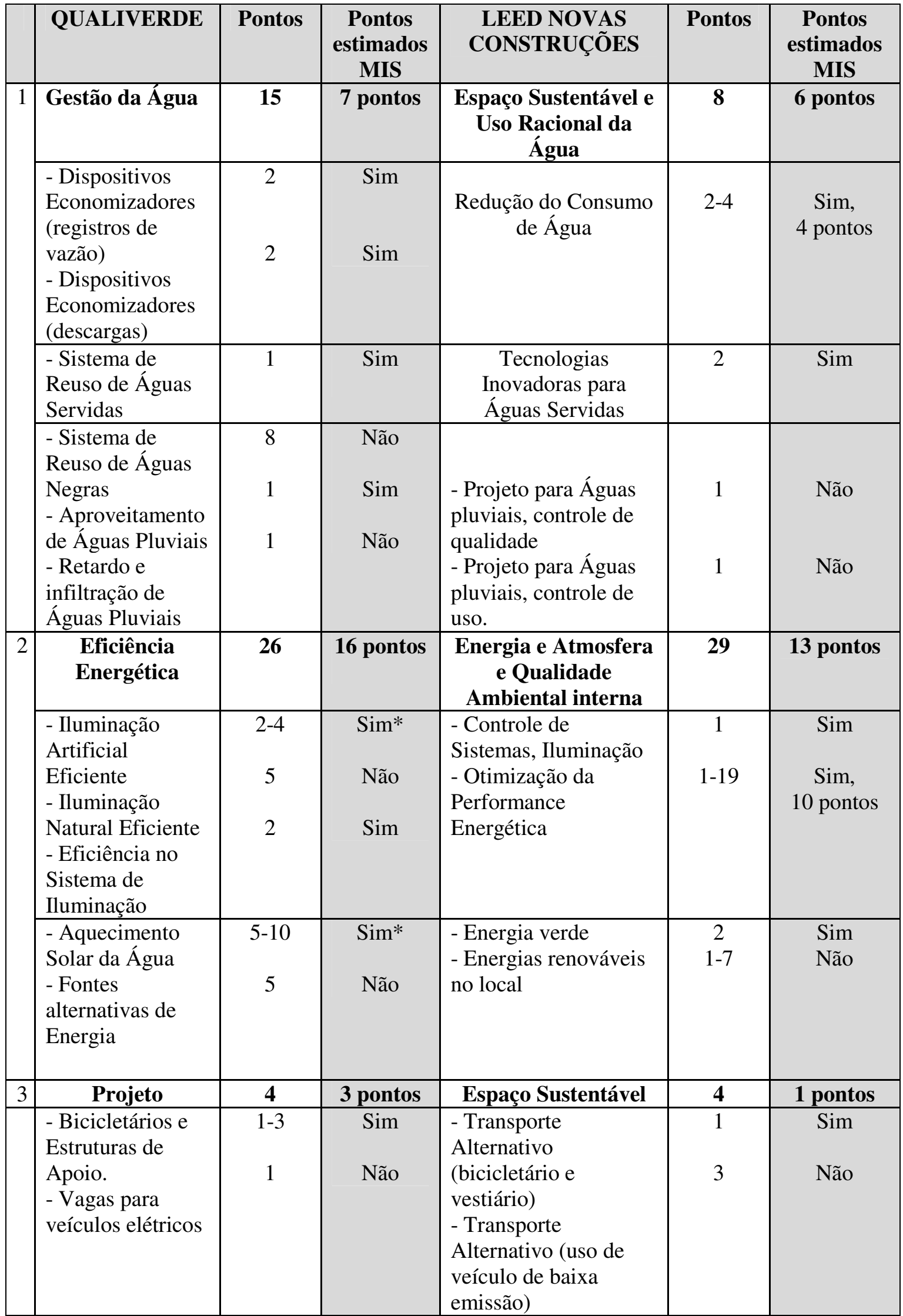

*Sem informação sobre a especificação.

Fonte: Adaptada de UGBC (2011) e COMPUR (2014) 
As exceções entre as certificações (requisitos que não possuem correlação entre os dois métodos) são apresentadas nos quadros 2 e 3.

\section{Quadro 2: Análise do Museu da Imagem e do Som - Exceções QUALIVERDE}

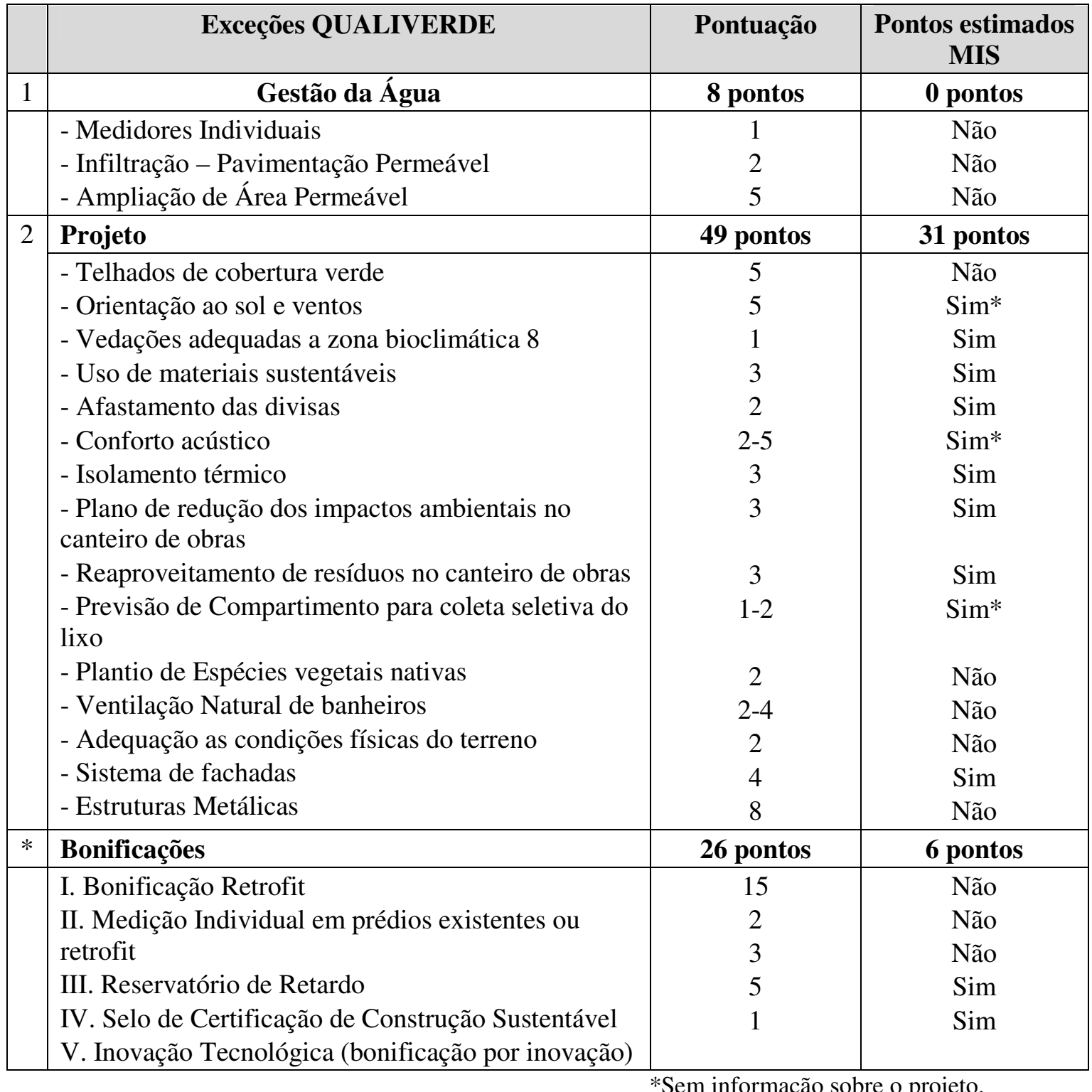

\section{Quadro 3: Museu da Imagem e do Som - Exceções LEED NC}

\begin{tabular}{|l|l|c|c|}
\hline & Exceções LEED NC & Pontuação & $\begin{array}{c}\text { Pontos estimados } \\
\text { MIS }\end{array}$ \\
\hline 1 & Espaço Sustentável & 20 pontos & $\mathbf{1 7}$ pontos \\
\hline & - Seleção do terreno & 1 & Sim \\
& - Densidade Urbana e Conexão & 5 & Sim \\
- Descontaminação de Áreas Poluídas & 1 & Não \\
- Transporte Alternativo, acesso ao transporte público & 6 & Sim \\
- Transporte Alternativo, área de estacionamento & 2 & Sim \\
- Desenvolvimento do espaço, proteção restauração do & 1 & Não \\
habitat & & Sim \\
\hline
\end{tabular}


Quadro 3: Museu da Imagem e do Som - Exceções LEED NC (continuação)

\begin{tabular}{|c|c|c|c|}
\hline & Exceções LEED NC & Pontuação & $\begin{array}{c}\text { Pontos } \\
\text { estimados MIS }\end{array}$ \\
\hline \multirow[t]{2}{*}{1} & Espaço Sustentável & \multicolumn{2}{|c|}{ (continuação) } \\
\hline & $\begin{array}{l}\text { - Redução da ilha de calor, áreas descobertas } \\
\text { - Redução da ilha de calor, áreas cobertas } \\
\text { - Redução da poluição luminosa }\end{array}$ & $\begin{array}{l}1 \\
1 \\
1\end{array}$ & $\begin{array}{l}\text { Sim } \\
\text { Sim } \\
\text { Não }\end{array}$ \\
\hline \multirow[t]{2}{*}{2} & Uso Racional da Água & 4 pontos & 4 pontos \\
\hline & - Uso eficiente de água no paisagismo & $2-4$ & Sim, 4 pontos \\
\hline \multirow[t]{2}{*}{3} & Energia e Atmosfera & 7 pontos & 7 pontos \\
\hline & $\begin{array}{l}\text { - Melhoria no comissionamento } \\
\text { - Melhoria na gestão de gases refrigerantes } \\
\text { - Medições e verificações }\end{array}$ & $\begin{array}{l}2 \\
2 \\
3\end{array}$ & $\begin{array}{l}\text { Sim } \\
\text { Sim } \\
\text { Sim }\end{array}$ \\
\hline \multirow[t]{2}{*}{4} & Materiais e Recursos & 14 pontos & 7 pontos \\
\hline & $\begin{array}{l}\text { - Reuso do Edifício, manter paredes, pisos e coberturas } \\
\text { existentes } \\
\text { - Reuso do Edifício, manter elementos interiores e não } \\
\text { estruturais } \\
\text { - Gestão de resíduos da construção } \\
\text { - Reuso de Materiais } \\
\text { - Conteúdo Reciclado } \\
\text { - Materiais Regionais } \\
\text { - Materiais de rápida renovação } \\
\text { - Madeira certificada }\end{array}$ & $\begin{array}{l}1-3 \\
1 \\
1-2 \\
1-2 \\
1-2 \\
1-2 \\
1 \\
1\end{array}$ & $\begin{array}{l}\text { Não } \\
\text { Não } \\
\text { Sim } \\
\text { Não } \\
\text { Sim } \\
\text { Sim } \\
\text { Não } \\
\text { Sim }\end{array}$ \\
\hline \multirow[t]{2}{*}{5} & Qualidade Ambiental Interna & 14 pontos & 7 pontos \\
\hline & $\begin{array}{l}\text { - Monitoração de ar externo } \\
\text { - Aumento da ventilação } \\
\text { - Plano de gestão da qualidade do ar, durante a construção } \\
\text { - Plano de gestão da qualidade do ar, antes da ocupação } \\
\text { - Materiais de baixa emissão, adesivos e selantes } \\
\text { - Materiais de baixa emissão, tintas e vernizes } \\
\text { - Materiais de baixa emissão, carpetes e sistemas de piso } \\
\text { - Materiais de baixa emissão, madeiras compostas e } \\
\text { agrofibra } \\
\text { - Controle Interno de poluentes e produtos químicos } \\
\text { - Controle de Sistemas, conforto térmico } \\
\text { - Conforto térmico, projeto } \\
\text { - Conforto térmico, verificação } \\
\text { - Iluminação Natural e paisagem, luz do dia } \\
\text { - Iluminação natural, vistas }\end{array}$ & $\begin{array}{l}1 \\
1 \\
1 \\
1 \\
1 \\
1 \\
1 \\
1 \\
1 \\
1 \\
1 \\
1 \\
1 \\
1 \\
1 \\
1\end{array}$ & $\begin{array}{l}\text { Não } \\
\text { Sim } \\
\text { Sim } \\
\text { Sim } \\
\text { Sim } \\
\text { Sim } \\
\text { Não } \\
\text { Não } \\
\text { Sim } \\
\text { Não } \\
\text { Sim } \\
\text { Não } \\
\text { Não } \\
\text { Não }\end{array}$ \\
\hline \multirow[t]{2}{*}{6} & Inovação e Processos de Projeto & 6 pontos & 6 pontos \\
\hline & $\begin{array}{l}\text { - Performance Exemplar - Transporte público } \\
\text { - Performance Exemplar - Maximização dos espaços } \\
\text { abertos } \\
\text { - Performance Exemplar - Soluções inovadoras para } \\
\text { sistema de esgoto }\end{array}$ & $\begin{array}{l}1 \\
1 \\
1\end{array}$ & $\begin{array}{l}\text { Sim } \\
\text { Sim } \\
\text { Sim }\end{array}$ \\
\hline
\end{tabular}


Quadro 3: Museu da Imagem e do Som - Exceções LEED NC (continuação)

\begin{tabular}{|c|l|c|c|}
\hline & Exceções LEED NC & Pontuação & $\begin{array}{c}\text { Pontos } \\
\text { estimados MIS }\end{array}$ \\
\hline $\mathbf{6}$ & Inovação e Processos de Projeto & \multicolumn{2}{|c|}{ (continuação) } \\
\hline & - Inovação no projeto & 1 & Sim \\
& - Inovação no projeto & 1 & Sim \\
& - Profissional acreditado LEED & 1 & Sim \\
\hline $\mathbf{7}$ & Créditos Regionais & $\mathbf{4}$ pontos & $\mathbf{4}$ pontos \\
\hline & - Prioridades regionais & $1-4$ & Sim, 4 pontos \\
\hline
\end{tabular}

Segundo a análise realizada, o projeto do MIS-RJ pode completar 72 pontos no método LEED, o que o qualificaria para a certificação LEED Novas Construções nível Ouro. Entretanto, considerando a avaliação conforme o selo QUALIVERDE, verificou-se que MIS poderia receber até 63 pontos, o que não qualificaria o projeto para essa certificação uma vez que a pontuação mínima é de 70 pontos.

\section{CONCLUSÕES}

A partir da análise do projeto do Museu da Imagem do Som através dos requisitos definidos pelas certificações LEED Novas Construções e QUALIVERDE pode-se destacar alguns aspectos que destoam dentre as certificações. Tomando como exemplo a categoria Gestão da Água, de acordo com o QUALIVERDE, o projeto da edificação deve considerar estratégias tais como: adoção de dispositivos para controle de vazão, adoção de dispositivos para economia na descarga das bacias sanitárias, adoção do sistema de reuso de águas servidas, adoção de sistema de reuso de águas negras, adoção de sistema para reaproveitamento de águas pluviais e adoção de mecanismos para retardo e infiltração de águas pluviais. Este requisito poderia ser considerado equivalente, no LEED NC, aos requisitos de Projeto Sustentável e Uso Racional da Água. Porém, considerando as sete exigências do selo QUALIVERDE nesta categoria, o valor da pontuação obtida não seria compatível com o LEED NC, uma vez que no QUALIVERDE, são destinados 15 pontos para a avaliação desses requisitos, enquanto no LEED NC, a pontuação equivalente seria de apenas 8 pontos. Entretanto, cabe ressaltar que, mesmo sendo o QUALIVERDE o selo que disponibiliza mais pontos nessa área de avaliação, a pontuação obtida pelo Museu da Imagem e do Som nas duas certificações é bem próxima. Dos 15 pontos distribuídos pelo QUALIVERDE para o tópico Gestão da Água, 8 seriam atendidos pela edificação, já no LEED NC, dos 8 pontos, 6 são almejados e atendidos a priori no projeto MIS. Entre as demais categorias que coincidem nos dois selos (Tabela 1), a pontuação obtida pelo projeto da edificação apresenta certa coerência e proporção, não havendo nenhuma distorção que desperte atenção.

Através das tabelas constatou-se que os requisitos que podem ser pontuados pela certificação carioca possuem uma estrutura mais objetiva, uma vez que apresentam um número menor de subdivisões e considera uma pontuação maior para cada item. $\mathrm{O}$ Quadro 3 mostra que o LEED Novas Construções subdivide suas categorias em inúmeros requisitos que possuem um valor menor. Outra categoria de avaliação do selo norte-americano que merece destaque é quanto ao Transporte Alternativo - Acesso ao Transporte público (na categoria Espaço Sustentável), que equivale a 6 pontos na tabela LEED NC e não possui equivalência no QUALIVERDE. Além disso, tem-se grande 
diferenciação no que diz respeito qualidade ambiental interna, presente de forma mais detalhada no LEED-NC e atendida em boa parte pela edificação analisada.

Outra questão notável é a distinção entre os pontos de bonificação no QUALIVERDE e LEED NC onde o primeiro selo disponibiliza 26 pontos e o segundo apenas 10 pontos. Porém, o Museu atinge 6 pontos e 10 pontos, respectivamente, o que mostra a maior exigência e especificação para se atender à esse requisito no selo QUALIVERDE, enquanto o LEED NC permite maior liberdade à solução em relação à inovação proposta pelo projeto.

Dessa forma, a análise do projeto do Museu da Imagem e do Som permitiu verificar que, embora o projeto esteja em vias de receber a certificação LEED NC Ouro, não estaria apto a receber a certificação carioca. Ressalte-se que, como não foi possível realizar a análise projetual detalhadamente, uma vez que não tivemos acesso aos projetos executivos, os resultados obtidos com desta pesquisa não são definitivos em relação à esse projeto. Entretanto, o estudo revela-se válido na medida em que aponta as discrepâncias entre os sistemas de certificação que, embora semelhantes em alguns aspectos, apresentam sistemas distintos que impossibilitam a qualificação de projetos de maneira uniforme.

Portanto, a produção de edificações sustentáveis fica comprometida na medida em que não se disponibilizam métodos de certificação ambiental que sejam equivalentes. Questiona-se, portanto, a eficiência e eficácia dos métodos de certificação ambiental como ferramentas para efetivamente atestar a qualidade ambiental das edificações construídas.

\section{AGRADECIMENTOS}

As autoras agradecem ao CNPQ pelo fomento: bolsa de iniciação científica (PIBIC), bolsa de produtividade em pesquisa (PQ) e Edital Universal - ${ }^{\circ}{ }^{\circ}$ 14/2012.

\section{REFERÊNCIAS}

CIB - International Council for Research and Innovation in Building Construction. (2002) Agenda 21 for Sustainable Construction in Developing Countries - Discussion document CSIR Building and Construction Technology, Pretoria: ZA.

COMPUR. Qualiverde: Legislação para Construções Verdes, Disponível em <http://www2.rio.rj.gov.br/smu/compur/pdf/proposta_qualiverde.pdf> Acesso em jan. 2014

FUNDAÇÃO ROBERTO MARINHO. MIS RJ. Site Institucional. Disponível em $<$ http://www.frm.org.br> Acesso em 19 de fevereiro de 2014.

LEED 2009 Rating Selection Guidance, versão 4, USGBC, 2011

MIS - MUSEU DA IMAGEM E DO SOM, RIO DE JANEIRO. Site Institucional. Disponível em <http://www.mis.rj.gov.br/sustentabilidade/> Acesso em 19 de fevereiro de 2014.

PEREIRA, A. A., BERNARDINO, M. R. SALGADO, M.S. Certificações ambientais no Brasil: indicativo da situação $13^{\circ}$ Conferência Internacional da LARES.Anais.. São Paulo, 2013, p. 1-9

Projeto de Lei $\mathrm{n}^{\circ} 1415 / 2012$ Estabelece os benefícios fiscais para os empreendimentos que detenham a qualificação QUALIVERDE e dá outras providências (Disponível em < http://mail.camara.rj.gov.br/APL/Legislativos > acesso em julho de 2014)

USGBC - United States Green Building Council. Página Institucional. Disponível em: $<$ http://www.usgbc.org>. Acesso em 23 de abril de 2014. 